\title{
LEMBREMOS DAS VELHAS OBRAS LEXICOGRÁFICAS PARA REDIMENSIONAR O PAPEL DA LEXICOGRAFIA E DOS NOVOS DICIONÁRIOS
}

\author{
Adja Balbino de Amorim Barbieri Durão \\ Universidade Federal de Santa Catarina/CNPq \\ adjabalbino@gmail.com
}

Resumo: A visão que o senso comum foi forjando em nossa mente como referente para a palavra 'dicionário' leva-nos a pensar em um livro com muitas páginas que guarda o segredo de todas as palavras. Mas o dicionário nem sempre teve a forma de livro que permeia nosso imaginário. $\mathrm{O}$ dicionário tem uma gênese, a qual pode ser retomada a partir de diferentes pontos de vista. Por entendermos que a gênese do dicionário está imbricada com a história da escrita, optamos por tomar como ponto de partida o que Boisson, Kirtchuck e Béjoint (1991, p. 162 apud Welker, 2004, p. 61) chamaram de paleolexicografia, considerando as manifestações elaboradas na pré-história como proto-escrita e, consequentemente, como intróito para adentrar no território das tabuinhas sumérias e dos papiros egípcios, que nos legaram proto-dicionários, para, na sequência, visitar o recinto dos glossários medievais, ascendentes da lexicografia e dos dicionários clássicos, com o fim de chegar, por fim, na jurisdição dos dicionários elaborados em nossos dias.

Palavras-chave: lexicografia, história do dicionário.

Abstract: Remember the old lexicographic works in order to reassess
the role of lexicography and new dictionaries. The view that the common
sense forged in our minds as a reference for the word "dictionary" leads
us to think of a book with many pages that holds the secret of all words.
But the dictionary has not always had the book form that pervades our
imagination. The dictionary has a genesis that can be resumed based on
different points of view. As we understand that the genesis of the dic-
tionary is intertwined with the history of the writing, our starting point 
was based on what Boisson, Kirtchuck and Béjoint (1991, p. 162 cited in Welker, 2004, p. 61) called paleolexicography, considering the manifestations developed in the pre-history as proto-writing, and consequently, as an introduction for coming to the territory of the Sumerian tablets and Egyptian papyri, that have provided us with proto-dictionaries in order to visit the venue of the medieval glossaries, ancestor of the lexicography and classic dictionaries, with the purpose of coming, at last, to the dictionaries developed today.

Keywords: lexicography, dictionary history.

\section{Introdução}

\section{Pelos caminhos da paleolexicografia}

Embora o termo pré-história seja polêmico, pois desde que o homem foi colocado sobre a face da terra, este é um ser histórico, como bem sabemos, Daniel Wilson o propôs em 1851 para denominar o período no qual ainda não se faziam registros escritos.

Clottes (2008, p. 15), arqueólogo especializado na etapa pré-histórica e em pinturas em cavernas, caracteriza os homens que viveram nessa época da seguinte maneira:

Eran como nosotros. Tenían el mismo cerebro y la misma apariencia y estatura. Sus emociones eran las mismas. Les asustaba la muerte. Creían en el más allá. Tenían sus amores y alegrías, sus depresiones y sus fiestas (...) Nuestro linaje empieza en África hace unos 120.000 años (...) Emigran a Oriente Próximo. De allí siguen al este y llegan a Australia. Otros viajan al oeste y comienzan a poblar Europa hace 45.000 años (...) y no sólo sacan fuerzas para cazar y alimentarse, también tiempo para inventar el arte. Producen dos centenares de obras maestras y numerosas pinturas menos elaboradas (...) desde el año 35.000 hasta el 11.000 antes del presente (...). 
Se, por um lado, o homem da pré-história, rigorosamente, não usou a escrita sistêmica, por outro abriu as portas para esse uso quando elaborou admiráveis criações fixadas nas paredes e tetos de cavernas, em montanhas e pedras, no Paleolítico, o primeiro e mais longo período dessa etapa: as pinturas rupestres. O termo 'rupestre' (do latim rupes, que quer dizer 'rocha' e 'primitivo') faz referência a qualquer atividade humana executada diretamente sobre superfícies rochosas. Conquanto essas pinturas rupestres não possam ser classificadas como escrita propriamente dita, como assinala Fischer (2009, p. 20), elas são consideradas como proto-escrita quando interpretadas como forma de comunicação.

Para pintar, o homem do paleolítico empregou substâncias extraídas da natureza (incluindo seus próprios fluidos corporais e excrementos), aplicando-as com os dedos, com pincéis feitos de pelos de animais ou assoprando-as por talos ocos de plantas e por ossinhos de pássaros. Usou tons de ocre, marrom, vermelho e preto, aproveitando, algumas vezes, as imperfeições e as fissuras das superfícies rochosas para criar a sensação de volume, dando maior realismo às suas produções.

Pintou figuras geométricas, cabras, antílopes, cavalos e bisões, entre outros animais da época. Alguns dizem que pintavam animais pensando que dessa forma os dominariam de forma mágica. Outros, como Sánchez (2008, p. 16), fala que pintavam pelo prazer de pintar. Já Clottes pensa que as covas eram catedrais e que os que iam até elas para pintar eram iniciados em algum tipo de culto religioso:

Los dibujos más antiguos tienen unos 30.000 años $^{1}$ y los más modernos se realizaron a finales de la última glaciación. Durante aquel larguísimo período conservaran el mismo tipo de religión. Por eso muchos estudiosos sospechan que arte y religión están relacionados. Y que el primer arte de la humanidad es un arte sacro. (Clottes apud Sánchez, 2008, p. 15). 
Zatz (1991, p. 17) adverte: dificilmente saberemos o que levou o homem das cavernas a fazer essas pinturas. Mas sabemos que elas foram o primeiro passo que o homem deu no caminho da escrita. Portanto, ao trazer a tona as pinturas rupestres, também estamos trazendo, concomitantemente, os primórdios da escrita, e, em consequência, a gênese dos dicionários.

\section{Nos territórios dos proto-dicionários sumérios}

Conforme explicou Burgierman (1999, p. 52), até 1998, não se questionava que a Mesopotâmica (atual Iraque) fosse o berço da escrita sistêmica, porém novas descobertas arqueológicas no Egito e no Paquistão problematizaram essa certeza. Em 1998, numa tumba localizada em Abidos (Egito), foram encontradas cento e oitenta tabuinhas de argila grafadas e, em 1999, no Paquistão, em uma cidade da Índia antiga, chamada Harappa, se encontraram fragmentos de vasos com sinais gráficos supostamente modelados por um dravda. Os cientistas deduziram que os signos gráficos encontrados no Egito são proto-hieróglifos, embora continuem sem resposta para os signos gráficos atribuídos a um representante do povo dravda (Burgierman, 1999, p. 54). Diante dessas descobertas, alguns estudiosos passaram a defender a ideia de que a escrita se originou simultaneamente e de modo independente em várias partes do mundo. Nós assumimos o ponto de vista de que a escrita é resultado de um percurso de elaboração cada vez mais complexo, que iniciou com registros figurativos e esquemáticos (escrita pictográfica e ideogrática) até chegar ao patamar de escrita fonográfica (alfabética). Assim como Fischer (2009, p. 32), nós entendemos que:

(...) o peso da evidência acumulada leva a considerar que a idéia da escrita completa pode ter emergido apenas uma vez na história da humanidade. A partir de um repertório padronizado de pictogramas e símbolos, os sumérios da 
Mesopotâmia elaboraram o que desde então se tornou a ferramenta mais versátil da humanidade. Todos os outros sistemas de escrita e caracteres são, talvez, derivativos dessa única idéia original - foneticismo sistêmico- que emergiu entre 6.000 e 5.700 anos atrás na Mesopotâmia.

As contribuições dos sumérios no tocante à escrita e à constituição dos dicionários são incontestáveis. Para esse povo, a escrita, inicialmente, se destinava ao registro contábil das riquezas naturais, trabalhadores, impostos, plantações, taxas, estoques da coroa e do templo, salários e gastos. (Fischer, 2009, p. 24). Fischer (2009, p. 25-26) conta que os sumérios elaboraram símbolos que indicavam números, acompanhando-os de desenhos do objeto quantificado (pictogramas) ou signos-objetos (isto é, signos que associam imagens a palavras).

Encontraram-se inúmeros exemplares de fichas de argila moldadas no formato de cones e esferas em várias escavações arqueológicas na região habitada pelos sumérios, guardadas em 'envelopes' de argila (bulla) (Fischer, 2009, p. 25), 'etiquetados' em seu exterior (como etiquetamos os envelopes de papel para acondicionar cartas e outros materiais escritos nos dias de hoje). Cada ficha guardada numa bullax representava uma determinada mercadoria. O rótulo (ou etiqueta) da bulla remetia para o número e o tipo de mercadoria de que tratava o registro, dessa forma não era preciso abri-la (ou seja, quebrá-la) para saber o conteúdo a que remetia ou para desvendar sua quantidade. Os sumérios também elaboraram um sistema numérico baseado em pedras -as pedras de contar- que, assim como as fichas, também eram acondicionadas em bulla, permitindo que se "lesse" o tipo e o número de produtos que encerrava. Os sistemas de fichas e pedras de contar cooperaram para a formação da escrita, mas, limitavam-se ao registro de dados, não permitindo a transmissão de pensamentos ou de idéias abstratas.

O emprego de cada pictograma sumério foi sendo ampliado (por exemplo, o desenho de um 'pé' passou a referir tanto a 'pé', como a 'andando'). Depois, passaram a ser conjugados (por exemplo, 
'olho' + 'água' remetia para a idéia de 'chorando'), o que demonstra que os pictogramas foram evoluindo para ideogramas, já que passaram a representar idéias e já não apenas objetos. Os pictogramas, como vimos, são signos-objetos e os ideogramas, signo-palavras (Fisher, 2009, p. 29).

Apesar de todas as possibilidades representativas dos pictogramas e dos ideogramas, eles ainda restringiam a capacidade expressiva da escrita. Como explicou Coulmas (1983 apud Fisher, p. 27), somente quando se adentrou no território dos fonogramas, os quais simbolizam, mediante signos abstratos, os sons que constituem palavras, se entrou, efetivamente, no horizonte da escrita completa, daí que se diga que os fonogramas são signos-sons.

Entrada na etapa da escrita cuneiforme -do latim cuenus, 'cunha' e forma 'forma'), que assim como a pictográfica e a ideográfica era feita dentro de retângulos enfileirados, se passou a ter uma representação mais completa e simplificada que as anteriores.

Nas várias escolas existentes na Mesopotâmia, as crianças sumérias aprendiam a ler e escrever sua língua. Kramer (1996, p. 36 apud Welker, 2004, p. 61) comenta que os professores sumérios elaboravam repertórios léxicos que deveriam ser copiados e memorizados pelos alunos. Centenas de milhares de tabuinhas de argila que reúnem esse tipo de compilações lexicográficas foram desenterradas na Mesopotâmia no transcorrer dos séculos. Boisson, Kirtchuck e Béjoint (1991, p. 262 apud Welker, 2004 p. 61) afirmam que essas tabuinhas de exercícios de vocabulário são proto-dicionários. E Fischer (2009, p. 53) acrescenta: Os escribas compilaram os primeiros dicionários do mundo: listas de palavras, ordenadas de acordo com a pronúncia, forma do signo e sentido.

\section{Dos proto-dicionários monolíngues aos bilíngues}

A Mesopotâmia foi uma região altamente cobiçada por causa de sua localização entre os rios Tigre e Eufrates, propícia para o 
cultivo e apta para a sobrevivência. Aliás, a palavra Mesopotâmia significa 'entre rios'. Como os povos que disputavam as terras entre rios falavam línguas diferentes foi-se estabelecendo a prática de elaboração de repertórios bilíngues (sumério-acadiano, sumério-eblaíta, etc.), nos quais para cada palavra suméria se fornecia a sua tradução para outra língua. Esses repertórios, conforme observa Welker (2004, p. 62), tiveram importância tanto nos períodos de batalha como quando o sumério se tornou língua morta e as nações que conquistaram a Mesopotâmica queriam ter acesso aos documentos deixados por seus antigos habitantes.

Boisson, Kirtchuck e Béjoint (1991, p. 262 apud Welker, 2004 p. 62) ressaltam que, excetuando-se o dicionário monolíngue com definições, que só apareceria muito tempo mais tarde (na Grécia, na Índia e na China), foi na civilização suméria onde apareceram os paradigmas de quase todos os tipos de dicionários que existem na atualidade.

\section{No ambiente dos proto-dicionários egípcios}

Do mesmo modo que os sumérios, os egípcios criaram um sistema de escrita chamado hieróglifo (hierós = 'sagrado'; glypheîin $=$ esculpir e grámmata, 'letras' = letras sagradas esculpidas). $\mathrm{O}$ suporte preferencial da escrita egípcia, entretanto, não era a tabuinha de argila dos sumérios, mas o papiro.

Inicialmente, os escribas egípcios usavam somente hieróglifos, mas essa escrita foi sendo destinada apenas para usos sagrados e, foram sendo elaboradas outras formas de escrita para substitui-la. Segundo esclarece Higounet (2003, p. 41-42):

Ao lado dessa escrita monumental, os egípcios empregaram (...) uma escrita de desenho mais livre e mais rápido para seus usos cotidianos, a escrita chamada hierática (do grego hieratikos, "sagrado") (...) Ela era traçada em folhas 
de papiro, com uma haste de junco flexível, a nanquim, orientada da direita para a esquerda. Os sinais hieráticos derivam diretamente dos hieróglifos, por simplificação do desenho e pela acentuação de alguns detalhes característicos (...). Por sua vez, a escrita demótica (do grego demos, "o povo") se constituiu (...) a partir da escrita hierática. Seu sistema é o mesmo usado pela escrita hieroglífica, mas sua grafia simplificada.

Os egípcios elaboraram repertórios léxicos que consistiam, principalmente, em coleções temáticas de palavras (nomes de animais, plantas, partes do corpo, profissões, etc.) (Boisson, Kirtchuck e Béjoint, 1991, p. 269 apud Welker, 2004 p. 62-63), de ordenação aleatória $^{2}$, que eram usados no ensino da língua escrita às crianças. Portanto, os pequenos egípcios, como os sumérios, também usaram proto-dicionários em seu processo de aprendizagem linguística.

\section{Na trilha do alfabeto fenício}

A escrita cuneiforme dos sumérios serviu a muitas línguas diferentes, chegando, através dos cananeus aos fenícios. Por causa de suas peculiaridades, a escrita cuneiforme criava muitas dificuldades para registrar outros idiomas tipologicamente diferentes. $\mathrm{Na}$ tentativa de registrar seu idioma com maior propriedade, os fenícios converteram o alfabeto ${ }^{3}$ pictório usado por seus ancestrais cananeus em alfabeto não pictório, o que acabou levando a uma escrita mais simples e mais eficiente que a cuneiforme da Mesopotâmia e as hieroglífica, hierática e demótica do Egito. O alfabeto fenício compunha-se de vinte e duas consoantes e permitia a escrita fonética, que dada a sua eficácia, acabou espalhando-se por toda a região (entre 1050 e 850 a. C.). No século I a.C. (Fischer, p. 82-83), os gregos ${ }^{4}$ transformaram algumas consoantes fenícias em vogais, acrescentaram novos caracteres a esse alfabeto e passaram 
a escrever da esquerda para a direita ${ }^{5}$. O alfabeto fenício modificado pelos gregos foi adotado pelos romanos e chegou até nós.

\section{Na rota dos glossários medievais}

Como sabemos, a Europa romanizada falava latim. Após a queda do Império romano, porém, a cultura formal ficou restrita aos recintos monásticos. Nessa época, os monges copistas faziam anotações sobre palavras e expressões presentes nos manuscritos que copiavam. Essas anotações tornaram-se tão frequentes que receberam um nome: glosas. Inicialmente, as glosas eram feitas nas margens das páginas dos manuscritos (glosa marginal) ou entre suas linhas (glosa interlinear), podendo ser um comentário sobre um trecho do manuscrito ou uma tradução completa do fragmento em questão. Falando sobre o uso de glosas, e, por extensão, de glossários, Bustos Tovar (2000) destacou que estaban destinados a facilitar la interpretación de los textos latinos. Cuando el latín escrito se fue alejando de los modelos clásicos, la necesidad de utilizar estos lexicones fue mayor. Por ello proliferaron en toda la Romania.

Os monges copistas exerciam seu trabalho no scriptorium, localizado em mosteiros. Dividiam-se em dois grupos: o grupo dos pendolistas, que tinham por função copiar os códices, e dos miniaturistas, encarregados de iluminá-los. Havia pelo menos dois motivos que justificavam a função dos copistas: primeiro, através dessa atividade, os monges acreditavam estar prestando um serviço a Deus; segundo, os monges copiavam e iluminavam os manuscritos visando sua transmissão e perpetuação. Esse trabalho, entretanto, era penoso. Conta-se que eles permaneciam horas copiando e iluminando os códices sobre os joelhos, pranchas ou mesas, usando, para escrever, uma vareta ou uma pena de ganso, e, para iluminá-los, um grande arsenal de recursos. Os pendolistas, como explicam Rocha e Roth (2005, p. 24), tinham que ter a mes- 
ma caligrafia, para que um pedaço de um livro não ficasse diferente do outro, o que, naturalmente, aumentava a complexidade do seu trabalho. Em um manuscrito da época do imperador Carlos Magno (742-814 d.C.) se encontram algumas queixas de um copista, que reclama do frio excessivo, da hora da refeição que nunca chegava e da tinta que congelava. O relato de outro monge dessa época diz o seguinte: copiar manuscritos embaralha a vista, causa corcunda, encurva o peito e o ventre, dá dor nos rins. É uma rude provação para todo o corpo. E segue uma advertência: (...) Assim, leitor, vire delicadamente as páginas e não ponha os dedos sobre as letras.

Os manuscritos tinham um valor excessivamente alto, justificável, primeiramente, pelo suporte utilizado, que era principalmente o pergaminho. Como destaca Queiroz (p. 10), o pergaminho podia ser feito de pele de cordeiro, vitela, cabra e, às vezes, gazela, antílope ou avestruz. Para se obter uma folha grande de pergaminho se consumia a pele de um animal inteiro (Rocha e Roth, 2005, p. 23). Para que uma cópia da Bíblia fosse feita gastavam-se trezentos animais, já que o pergaminho podia ser escrito dos dois lados, economizando-se espaço (Rocha e Roth, 2005, p. 23). O valor dos manuscritos também estava relacionado ao fato de, muitas vezes, suas encadernações serem feitas com placas de ouro e de prata, decoradas com pedras preciosas e marfim. Comenta-se que a cópia de um exemplar de uma obra de Cícero ou de Sêneca, por exemplo, equivalia ao valor de um rebanho de carneiros, na proporção de uma cabeça por quatro fólios ${ }^{6}$ (folhas escritas dos dois lados).

Por causa de seu alto valor, os estudantes não adquiriam os livros: eles alugavam fragmentos de texto, consultavam-nos nas bibliotecas ou copiavam-nos. Ao consultar ou copiar parte dos manuscritos, os leitores eram expostos às glosas, ainda que seu propósito inicial não fosse estritamente consultá-las. As glosas, entretanto, foram se tornando imprescindíveis para o entendimento dos textos. Bustos Tovar (2000) reitera a ideia de que: 
(...) los usuarios de textos escritos necesitaban a menudo ayudas para interpretarlos. Éste es el origen de los glosarios que comienzan a redactarse en la Romania. Los comentarios y aclaraciones a los textos clásicos constituyen el origen de la tradición glosística que había de llegar a la Edad Media. Tales comentarios fueron cada vez más necesarios, a medida que la cultura clásica fue haciéndose más repetitiva y menos original.

Como se vê, o próprio uso das glosas foi reforçando a necessidade de se organizar o material léxico anexado nos manuscritos para que pudesse ser consultado com facilidade. As glosas marginais e interlineares, primeiramente, passaram a ser incluídas nos manuscritos em forma de apêndice ordenado aleatoriamente. Mais adiante, as glosas passaram a ser repertoriadas em ordem alfabética. Do ponto de vista formal, pode-se dizer que, ao organizarem as glosas alfabeticamente, os monges copistas concluíram o processo de criação da lexicografia e do dicionário como os entendemos hoje. Nesse sentido, as observações de Bustos Tovar (2000) lembram que:

En principio, pues, las glosas no eran repertorios léxicos, sino comentarios variados a los textos que era preciso explicar. A veces tenían la forma de diccionario, pero la intención de sus redactores no era la propia de un lexicógrafo, sino la de un recopilador del saber. A la caída del Imperio florecieron los glosarios (...). Surgió al mismo tiempo un tipo de obra con mayor carácter lexicográfico, constituyendo repertorios de sinónimos y de "diferencias de palabras". De entre los primeros destacan las famosas Synonima Ciceronis o Synonima Calligere. (...) Por otra parte, el Libro X de las Etymologial, De Vocabulis, sí constituyeron un verdadero repertorio lexicográfico. Lo cierto es que al llegar el siglo VIII (...) hay en toda Europa una verdadera tradición glosística consolidada. 
Com o aumento do número de estudantes foi sendo necessário produzir novas cópias de manuscritos, por isso a função de copista passou a ser exercida também por leigos (sob supervisão das universidades). Dessa forma, ao mesmo tempo que as glosas iam passando a ser cada vez mais cotidianas e usadas pelos leitores dos manuscritos, que buscavam nelas explicações para as dúvidas surgidas durante a leitura, o livro ia perdendo seu caráter de objeto de luxo para assumir uma feição mais rotineira.

O mais célebre repertório léxico da Idade Média foi o dicionário latim-italiano, publicado por, Ambrogio Calepino, um monge italiano, em 1502, em Reggio Emilia (Itália), obra que foi traduzida por outros compiladores para várias outras línguas (francês, alemão, inglês, espanhol, dálmata, húngaro, boêmio, polaco, etc.). (Martínez de Sousa, 2009, p. 20). O dicionário Calepino teve uma fama tão grande que esse nome acabou se consagrando como sinônimo de 'dicionário'. Boisson, Kirtchuck e Béjoint (1991, p. 285 apud Welker, 2004 p.) explicam que dicionários bilíngues que tinham o latim como língua de partida ou língua de chegada acabaram por inspirar os lexicógrafos na elaboração de dicionários bilíngues para duas línguas vernáculas.

A necessidade de elaborar ferramentas úteis para a tradução eram enormes no século XIII a XV, demanda que acelerou a elaboração de dicionários bilíngues. No século XVIII, a necessidade passou a ser a elaboração de obras lexicográficas que dessem conta do registro, da consulta e do ensino de línguas. No século XIX, o dicionário, a gramática e os livros de textos passaram a encabeçar os materiais ideais para manter a regulação das línguas. No século $\mathrm{XX}$, após serem fomentados vários tipos de dicionários que refletem os avanços técnicos e científicos das sociedades modernas, a lexicografia e, consequentemente, os dicionários passaram a ser elaborados à luz desses avanços, produzindo-se em $C D$-rom e em versões on-line. 


\section{Caminhando para algumas conclusões}

Começamos por correlacionar a história dos dicionários à história da escrita, tomando as pinturas rupestres como proto-escrita. Posteriormente, mostramos que a tradição de coletar e organizar palavras em forma de listas remonta ao tempo das tabuinhas sumérias e aos papiros egípcios, povos que elaboraram proto-dicionários. Retomamos a idéia de que, com a ascensão das línguas vernáculas, foi-se estabelecendo a tradição de anexar glosas nos manuscritos medievais, revelando como se desencadeou a gênese das obras lexicográficas, a partir de glosas.

Muitas definições têm sido dadas ao longo do tempo para o dicionário: livro com muitas páginas que guarda o segredo de todas as palavras, como falamos na introdução deste trabalho, pai dos burros, tesouro léxico, obra de referência... Entre os vários objetivos que os dicionários podem cumprir, destaca-se seu emprego como ferramenta de aprendizagem lingüística. Os sumérios, os egípcios e os medievais o usaram como ferramenta de aprendizagem e/ou aperfeiçoamento lingüístico. Assim, nós também podemos e devemos fazê-lo. Independentemente da visão que se tenha sobre o dicionário, sabe-se que ele é um repertório léxico organizado sistematicamente e que, por sua própria configuração textual, disposta em uma ou mais colunas separadas por corondéis (linhas de separação) ou por corondéis cegos (espaços em branco entre as colunas), orientada pela presença de palavras-guia (que indicam as unidades léxicas compreendidas em cada página), pela estruturação de sua macroestrutura (ou seja, das entradas ou palavras da nomenclatura), e de sua microestrutura (formada pelos verbetes, ou seja, pelas informações lingüísticas referentes a cada entrada), e que, quando é monolíngue, oferece definições, e, quando é bilíngüe, traduções ou equivalentes, o dicionário não pode ser confundido com qualquer outro tipo de livro.

Krieger, 2006, p. 141-142 mostra que: 
(...) sob a aparente simplicidade de uma lista alfabética, da qual cada palavra é o lema (...) a sociedade costum[a] compreender o dicionário como resultado apenas de um saber-fazer pragmático que pressupõe o domínio de uma fácil técnica de compilação de palavras, cujos usos e significados já são consagrados. Essa equivocada compreensão ganha maior concretude na medida em que o dicionário aparenta ser um objeto somente representativo de um saber lingüístico coletivo, sem interferência do lexicógrafo. Entretanto, a obra dicionarística não se resume a uma listagem, mas, como um texto, possui regras próprias de organização. Nessa regularidade organizacional, há projetos específicos definidos em conformidade com os fins visados pelo lexicógrafo, que imprime suas marcas subjetivas e ideológicas em sua obra.

Efetivamente, a visão de que o dicionário se baseia meramente no emprego de técnica lexicográfica permeou (e, infelizmente, ainda permeia) a facção de uma quantidade significativa de obras lexicográficas. Haensch e Omeñaca (2004, p. 20) mostram que até bem entrado o século XX, a lexicografia realmente consolidou uma trajetória meramente circunstancial, ao dizerem que: (...) "la lexicografia nació y se fue desarrollando en un ámbito precientífico de una manera empírica, rutinaria, sin una teoría lingüística coherente que pudiera servirle de base, desarrollando sus métodos y sus técnicas, por así decirlo, 'sobre la marcha'”. Esse caráter pré-científico veio a ser matizado tão somente depois da II Guerra Mundial, quando os lexicógrafos começaram a deixar a concepção de lexicografia como 'arte' ou 'técnica' de lado, aproximando-se das disciplinas lingüísticas e voltando-se para a reflexão sobre os dicionários do ponto de vista de sua história, de sua estrutura, de sua tipologia e da ponderação das funções que justificam a elaboração de cada obra lexicográfica. Dessa reflexão foi que nasceu a lexicografia teórica (ou metalexicografia) e a lexicografia prática. 


\section{Notas}

1. Ressalte-se que a questão temporal continua sendo uma incógnita, porque os métodos utilizados para determiná-la nem sempre levam a resultados fiáveis por causa da acumulação de resíduos no transcurso do tempo.

2. Somente em torno do século III d.C., provavelmente por influência dos gregos, os egípcios começaram a organizar repertórios monolíngues em ordem alfabética.

3. O alfabeto (do latim alphabetum, que se compõe do nome das duas primeiras letras do alfabeto grego -alfa e beta-), diferentemente da escrita pictográfica e da ideográfica, permite a escrita fonográfica, ou seja, a escrita que decompõe as palavras em sons mediante o uso de signos abstratos.

4. Ressalte-se que foi também no século I que os gregos criaram os verbetes, acompanhando as palavras de informação sobre suas acepções e usos correspondentes.

5. Os fenícios escreviam da direita para a esquerda.

6. Um fólio, seguindo Queiroz (p. 10) equivale a uma folh a medindo entre 35 a $50 \mathrm{~cm}$ de altura e 25 a $30 \mathrm{~cm}$ de largura. 


\section{Bibliografia}

BÉJOINT, Henri. Modern Lexicography. An Introduction. Oxford. Oxford University Press, 2000.

BURGIERMAN, Denis Russo. "O primeiro dia da história”. Super Interessante, 7: 52-57, 1999.

BUSTOS TOVAR, José Jesús. "El uso de glosarios y su interés para la historia de la lengua". Actas de la X Semana de Estudios Medievales. La Enseñanza en la Edad Media. Nájera: Instituto de Estudios Riojanos, 2000. Disponível em: http://www.dialnet.unirioja.es/servlet/dcfichero_artículo?codigo $=566420$. thm (Acesso: 26/09/2010).

FISCHER, Steven Roger. História da escrita. Trad. Mirna Pinsky. São Paulo: Editora UNESP, 2009.

HAENSCH, Günther; OMEÑACA, Carlos. Los diccionarios del español en el siglo XXI. 2 ed. Salamanca: Ediciones Universidad de Salamanca, 2004.

HIGOUNET, Charles. História concisa da escrita. Trad. Marcos Marcionilo. São Paulo: Parábola, 2003.

KRIEGER, Maria da Graça. "Tipologias de dicionários: registros de léxico, princípios e tecnologias”. Calidoscópio 4/3: 141-147, 2006.

MARTÍNEZ CELIS, Diego; BOTIVA CONTRERAS, Álvaro. Introducción al arte rupestre. Disponível em: http://www.rupestreweb.info/introduccion.html" (Acesso: 26/09/2010)

MARTÍNEZ DE SOUSA, J. Manual de lexicografía. Gijón: Trea, 2009.

QUEIROZ, Rita de C. R. de. "A informação escrita: do manuscrito ao texto virtual". Disponível em http://www.dici.ibict.br/00000513/01/RitaQueiroz.pdf (Acesso: 09/10/2010) 
RANGEL, Egon de Oliveira; BAGNO, Marcos. Dicionários em sala de aula. Brasília: Ministério de Educação. Secretaria de Educação Básica, 2006. Disponível em: http://www.portal.mec.gov.br/seb/arquivos/pdf/Avalmat/polleidicio.pdf (Acesso 16/10/2010).

ROCHA, Ruth; ROTH, Otávio. A história do livro. São Paulo: Melhoramentos, 2005.

(s/a.) "ABC é resultado de uma sucessão de plágios". Super Interessante, abril: 52-57, 2009. (s/a.) "Pintura rupestre". Disponível em: http://www.es.wikipwsi. org/wiki/pintura_rupestre (Acesso: 26/09/2010).

SÁNCHEZ, Carlos Manuel. "Retrato del artista cromañón". SL Semanal, : 1420, de 24 de agosto de 2008, 14-20.

WELKER, Herbert Andreas. Dicionários. Uma pequena introdução à Lexicografia. $2^{\mathrm{a}}$. edição. Brasília: Thesaurus, 2004.

ZATZ, Lia. Aventura da escrita: história do desenho que virou letra. São Paulo: Moderna, 1991. 
